\title{
Pemanfaatan Layanan Web Keanekaragaman untuk Pengelolaan Informasi Tumbuhan Obat Indonesia
}

\section{Utilization of Biodiversity Web Services For Indonesian Medicinal Plant Information Management}

\author{
SUWANTO SANJAYA ${ }^{12^{*}}$, YENI HERDIYENI $^{1}$, IRMAN HERMADI $^{1}$
}

\begin{abstract}
Abstrak
Penelitian ini mengusulkan pemanfaatan layanan web keanekaragaman hayati untuk pengelolaan informasi tumbuhan obat Indonesia. Penyedia layanan web keanekaragaman hayati yang digunakan adalah Global Biodiversity Information Facility (GBIF) dan Encyclopedia of Life (EOL). Layanan web tersebut dimanfaatkan untuk melengkapi informasi tumbuhan obat Indonesia. Penyedia layanan web keanekaragaman hayati tersebut memiliki fasilitas untuk membagikan informasi yang dimilikinya. Fasilitas yang disediakan adalah Application Programming Interface (API). Parameter utama yang digunakan untuk mendapatkan informasi-informasi yang diinginkan adalah nama spesies tumbuhan. Hasil penelitian menunjukkan bahwa GBIF dan EOL dapat dijadikan sebagai sumber infomasi tumbuhan obat Indonesia. Integrasi antara GBIF dan EOL dapat menghasilkan informasi tumbuhan obat menjadi lebih banyak dan beragam.
\end{abstract}

Kata kunci: API, EOL, GBIF, layanan web, tumbuhan obat

\section{Abstract}

This research proposes utilization of biodiversity web services for Indonesian medicinal plant information management. We used Global Biodiversity Information Facility (GBIF) dan Encyclopedia of Life (EOL) as providers of biodiversity web service. The web service was used to add information of Indonesian medicinal plant. The providers of biodiversity web service have the method to information sharing. The method was called the Application Programming Interface (API). We used name of the species as the main parameter. The result showed that the GBIF and EOL can be used as information resources of Indonesian medicinal plant. The integration of GBIF and EOL made the information of Indonesian medicinal plant become more numerous and diverse.

Keywords: API, EOL, GBIF, medicinal plant, web service

\section{PENDAHULUAN}

Indonesia memiliki keanekaragaman hayati yang besar yaitu lebih dari 38.000 spesies (Bappenas 2003). Keanekaragaman hayati terdiri dari spesies tumbuhan dan hewan. Salah satu keanekaragaman hayati yang harus dilestarikan adalah tumbuhan obat. Cara yang dapat digunakan untuk melestarikannya adalah mengenali tumbuhan obat (Hamzari 2008). Pengenalan tumbuhan obat dapat dilakukan dengan mempelajari tingkatan takson dalam taksonomi tumbuhan (Tjitrosoepomo 2005). Informasi-informasi tingkatan takson tumbuhan dan informasi lain yang dapat digunakan untuk mengenali tumbuhan obat telah banyak tersebar di berbagai situs web. Beberapa situs web penyedia (provider) layanan informasi tumbuhan adalah Global Biodiversity Infomation Facility (GBIF), Encyclopedia of Life (EOL), Integrated Taxonomy Information System (ITIS).

\footnotetext{
${ }^{1}$ Departemen Ilmu Komputer, Fakultas Matematika dan Ilmu Pengetahuan Alam, Institut Pertanian Bogor, Bogor ${ }^{2}$ Program Studi Teknik Informatika, Fakultas Sains dan Teknologi, UIN Sultan Syarif Kasim Riau

*Penulis Korespondensi: Tel/Faks: +62852-71922778; Surel: suwantosanjayauin-suska.ac.id
} 
Informasi tumbuhan obat sangat beraneka ragam, seperti informasi manfaat, lokasi penyebaran, taksonomi dan sebagainya. Beberapa informasi seperti lokasi penyebaran, dan manfaat dapat membuat informasi sendiri, tetapi untuk informasi taksonomi tumbuhan tidak disarankan untuk membuat informasinya sendiri. Hal ini disebabkan informasi taksonomi dapat berubah jika ada temuan ilmiah baru (Tuominen et al. 2011). GBIF adalah salah satu penyedia layanan informasi yang sudah menggunakan standar informasi keanekaragaman hayati internasional khususnya informasi taksonomi (Wieczorek et al. 2012). Oleh karena itu, pemanfaatan layanan web keanekaragaman hayati merupakan alternatif yang dapat digunakan untuk melengkapi informasi taksonomi dan informasi lain yang disediakan oleh masing masing penyedia informasi.

Layanan web adalah sebuah metode komunikasi atau pertukaran data antara aplikasi yang berbeda (Benslimane et al. 2008). Beberapa situs web keanekaragaman hayati menyediakan layanan untuk berbagi informasi menggunakan sekumpulan perintah atau fungsi sebagai antarmukanya. Sekumpulan perintah atau fungsi tersebut lebih dikenal dengan Application Programming Interface (API). Setiap layanan memiliki cara tersendiri untuk berbagi informasinya. API yang digunakan setiap layanan web memiliki perbedaan, tetapi ada juga yang mengintegrasikan API tersebut untuk menghasilkan informasi yang lebih beragam.

Penelitian tentang pemanfaatan layanan web telah banyak dilakukan, seperti pemanfaatan Google Maps API untuk membantu ahli biologi dalam pengelolaan data spesimen yang dikumpulkan dilapangan (Tavares et al. 2011). Flemons at al. (2007) memanfaatkan informasi layanan web GBIF untuk memvisualisasikan dan menganalisis distribusi keanekaragaman hayati. Constable et al. (2010) juga memanfaatkan layanan web GBIF untuk mengembangkan basisdata vertebrata. Berdasarkan penelitian-penelitian tersebut, layanan web dapat dimanfaatkan sebagai fasilitas untuk menambah informasi-informasi keanekaragaman hayati khususnya informasi tumbuhan obat.

Berdasarkan latar belakang dan beberapa penelitian terkait, masalah yang dapat dirumuskan adalah bagaimana memanfaatkan API yang terdapat pada layanan web keanekaragaman hayati. Pemanfaatan API tersebut untuk melengkapi informasi tumbuhan obat Indonesia. Penyedia layanan web yang digunakan pada penelitian ini adalah GBIF dan EOL. Tujuan penelitian ini adalah memanfaatkan penyedia layanan web keanekaragaman hayati untuk melengkapi informasi tumbuhan obat Indonesia dan mengusulkan prototipe sistem informasi tumbuhan obat Indonesia.

\section{METODE}

Tahapan penelitian yang dilakukan pada penelitian ini mengikuti tahap pengembangan prototipe yang digunakan oleh Pressman (2010). Tahapan-tahapan tersebut dimodifikasi dan disesuaikan dengan kebutuhan penelitian. Secara umum tahapan yang dilakukan pada penelitian ini adalah pengumpulan kebutuhan, perencanaan pengembangan prototipe, perancangan prototipe, dan pembuatan prototipe. Tahap-tahap yang dilakukan pada penelitian ini yaitu pengumpulan kebutuhan, perencanaan pengembangan prototipe, perancangan prototipe, dan pembuatan prototipe.

Pengumpulan kebutuhan dilakukan untuk mengidentifikasi kebutuhan data dan informasi tumbuhan obat. Data yang digunakan adalah data hasil penelitian tentang kajian etnobotani pemanfaatan tumbuhan obat (Jumali 2006). Data yang digunakan pada penelitian ini adalah nama spesies tumbuhan obat dalam bahasa Indonesia dan bahasa Latin.

Pada tahap perencanaan yang dilakukan adalah merencanakan penelitian dan merumuskan masalah penelitian. Penelitian ini dibutuhkan karena informasi-informasi tentang tumbuhan obat sudah banyak terdapat diberbagai situs web keanekaragaman hayati. Penggunaan kembali informasi yang sudah ada akan lebih menghemat sumber daya, sehingga pemanfaatan layanan web keanekaragaman hayati akan lebih efektif daripada membuat informasi sendiri. 
Pada tahap perancangan prototipe yang dilakukan adalah merancang masukan (input) yang akan digunakan dan keluaran (output) yang ingin dihasilkan. Selanjutnya merancang antarmuka pengguna (user interface). Antarmuka pengguna hanya ditujukan untuk pengguna umum. Pengguna umum dapat mencari informasi tumbuhan obat berdasarkan masukan nama spesies tumbuhan obat. Berdasarkan data masukan tersebut, pengguna dapat melihat informasinformasi seperti informasi taksonomi tumbuhan obat, sinonim, gambar, referensi yang digunakan, dan informasi lainnya.

Pada tahap pembuatan prototipe yang dilakukan adalah proses penulisan program dan pengujian prototipe informasi tumbuhan obat Indonesia. Penulisan kode program menggunakan bahasa pemrograman PHP. Pengujian dilakukan dengan menggunakan kata kunci nama spesies tumbuhan dalam bahasa Indonesia dan Latin.

Peralatan yang digunakan pada pengembangan prototipe informasi tumbuhan obat Indonesia adalah perangkat lunak dan perangkat keras. Perangkat lunak yang digunakan adalah Notepad++ v6.5.1, XAMPP v1.7.3. Perangkat keras yang digunakan adalah laptop dengan spesifikasi processor Intel(R) Core(TM) 2 Duo CPU P7450 @2.13GHz, Memory 4 GB, Hardisk 500 GB.

\section{HASIL DAN PEMBAHASAN}

Setiap penyedia layanan informasi keanekaragaman hayati memiliki kelengkapan informasi yang berbeda-beda. Percobaan terhadap API GBIF dan EOL harus dilakukan untuk melihat informasi apa saja yang terdapat didalamnya. Hal ini berguna untuk merancang informasi yang ditampilkan pada pengguna. Bentuk data yang disediakan oleh GBIF dan EOL adalah JSON (JavaScript Object Notation).

GBIF menyediakan beberapa API yang dapat digunakan untuk menggunakan informasi yang dimilikinya. Fungsi API untuk pencarian spesies yang disediakan GBIF adalah match, search, dan suggest (GBIF 2014). Fungsi API yang digunakan pada penelitian ini adalah match karena lebih flexibel dalam pencariannya. Fungsi tersebut digunakan untuk mendapatkan informasi taksonomi menggunakan metode fuzzy. Parameter yang digunakan adalah name dan verbose. Parameter name adalah nama spesies tumbuhan. Parameter verbose untuk menentukan pilihan informasi yang dihasilkan. Contoh penggunaan fungsinya adalah http: //api.gbif.org/v0.9/species/match?verbose=fal se\&name=Andrographiso20pa niculata. Verbose bernilai false berarti hanya mengembalikan hasil pencarian informasi spesies Andrographis paniculata yang memiliki tingkat kesesuaian tertinggi. Andrographis paniculata adalah nama ilmiah dari tumbuhan Sambiloto. Hasil pemrosesan fungsi pada contoh tersebut dapat dilihat pada Gambar 1.

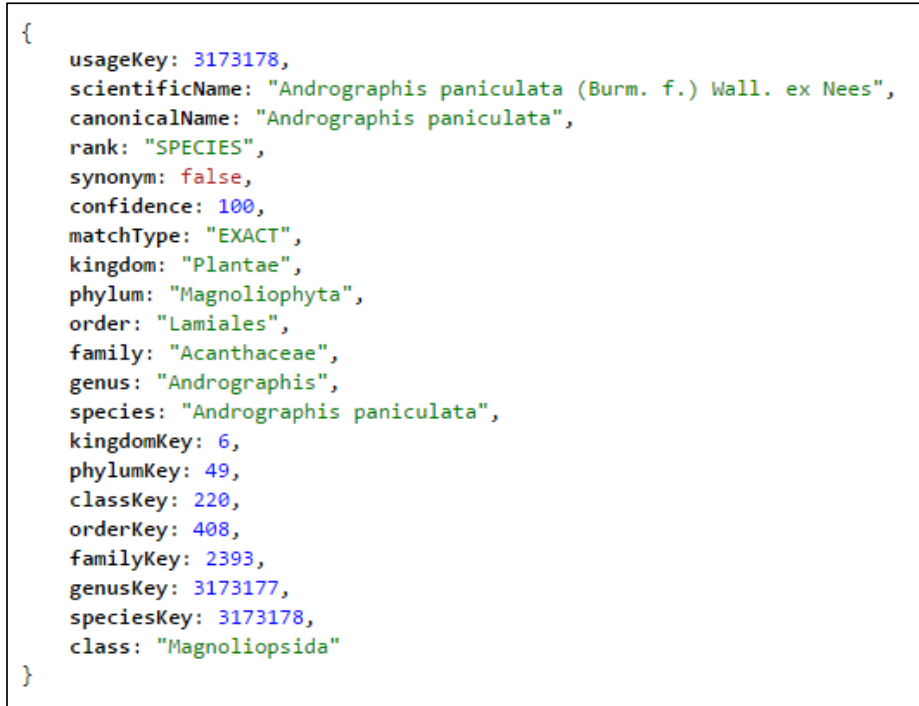


GBIF memiliki fungsi API untuk menghasilkan informasi gambar, referensi, sinonim, dan nama lokal di negara lain. Fungsi yang digunakan adalah images, references, synonyms, dan vernacularNames (GBIF 2014). EOL juga menyediakan beberapa API yang dapat digunakan untuk menggunakan informasi yang dimilikinya. Fungsi API yang disediakan seperti ping, pages, search, collections, data_objects, hierarchy_entries, hierarchies, provider_hierarchies, dan search_by_provider (EOL 2014). Fungsi API yang digunakan adalah search karena parameter yang digunakan adalah nama spesies tumbuhan. Contoh penggunaan fungsinya adalah http://eol.org/api/search/1.0.json?q=Andrographist paniculata \&page=1\&exact=false\&filter_by_taxon_concept_id=\&filter_by_hierarc hy_entry_id=\&filter_by_string $=\& c a c h e \_t t l=60000$. Hasil pemrosesan fungsi pada contoh tersebut dapat dilihat pada Gambar 2.

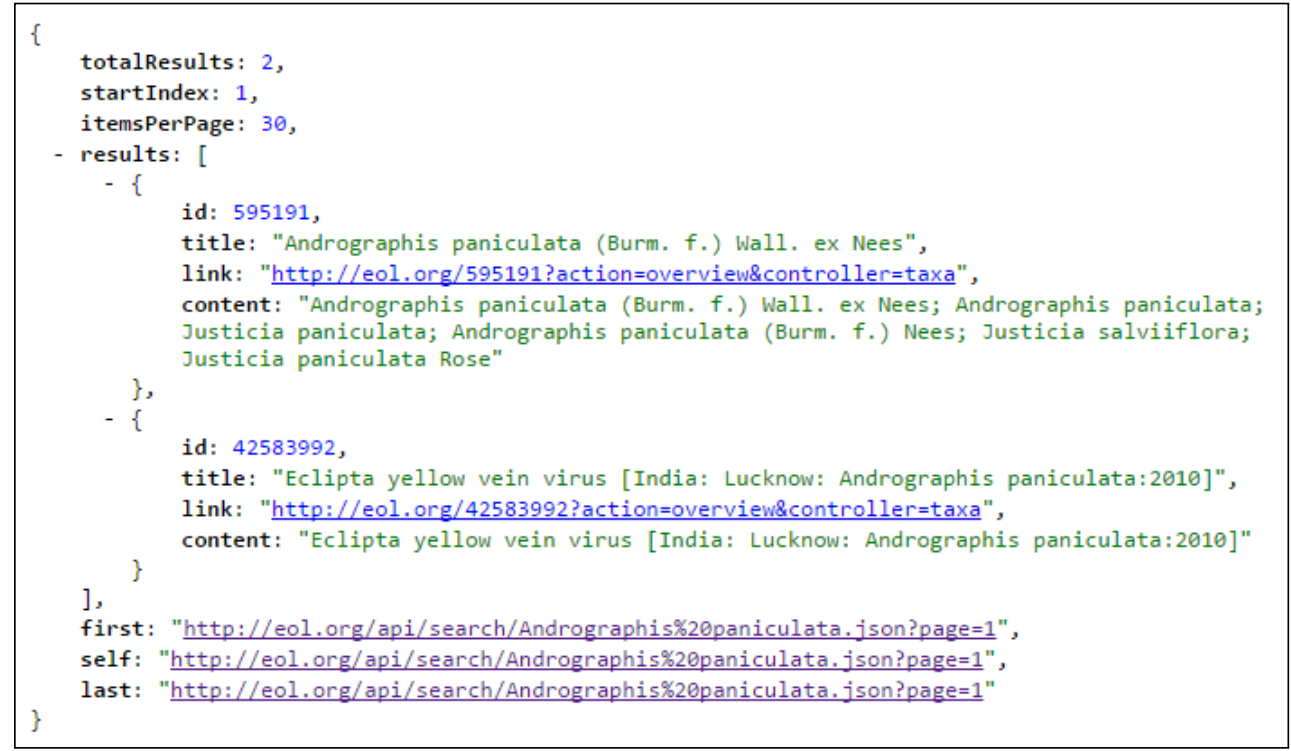

Gambar 2 Hasil pemrosesan fungsi search

Selain itu EOL juga terintegrasi dengan layanan web lainnya, khususnya GBIF. EOL menyediakan API berdasarkan penyedia informasi menggunakan parameter "provider". Fungsi API yang digunakan adalah search_by_provider. Informasi yang diambil dari EOL menggunakan kode spesies yang didapatkan dari GBIF. Contoh penggunaan fungsinya adalah http://eol.org/api/search_by_provider/1.0/3173178.json?hierarchy_id=800\&cac he_tt $1=60000$. "3173178" adalah kode spesies yang dihasilkan dari GBIF. Kode provider GBIF pada EOL adalah "800". Hasil pemrosesan fungsi pada contoh tersebut dapat dilihat pada Gambar 3.

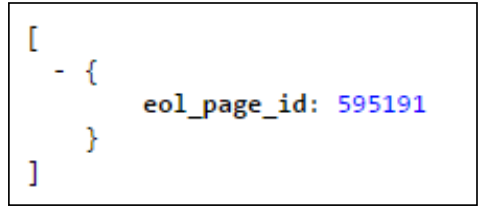

Gambar 3 Hasil pemrosesan fungsi search_by_provider

Data yang dihasilkan dari proses tersebut berupa kode halaman EOL. Selanjutnya kode halaman tersebut diproses menggunakan fungsi pages. Contoh penggunaan fungsinya adalah http: / / eol . org/api/pages / 1.0/595191. j son? images $=10$ \&videos $=10 \&$ sounds $=10$ \&maps $=10$ \&text $=10 \& i u c n=f a l$ se\&subjects=overview\&licenses=all \&details=true\&common_n ames=true\&synonyms=true\&references=true\&vetted=0\&cache_tt $1=60000$. 
adalah kode halaman yang dihasilkan dari pemrosesan fungsi search_by_provider. Hasil pemrosesan fungsi pada contoh tersebut dapat dilihat pada Gambar 4.

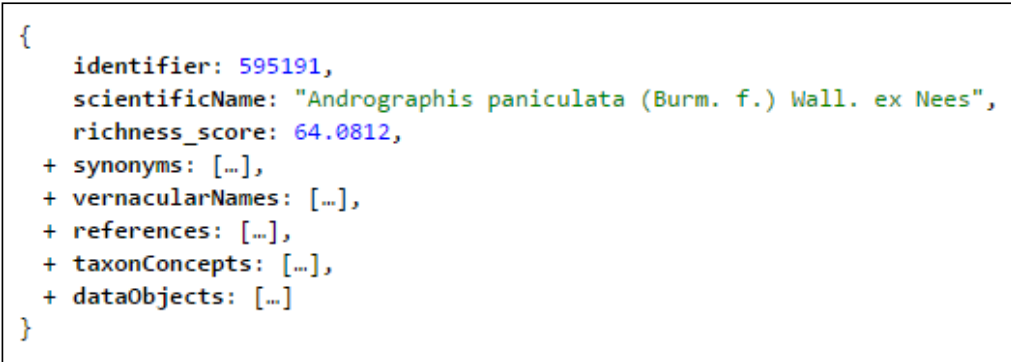

Gambar 4 Hasil pemrosesan fungsi pages

Berdasarkan percobaan penggunaan fungsi API pada setiap penyedia layanan web, informasi taksonomi tumbuhan yang digunakan adalah GBIF karena informasinya lebih rinci. Sedangkan untuk informasi gambar, referensi, sinonim, dan nama lokal di negara lain yang digunakan adalah informasi dari GBIF dan EOL. Integrasi atau penggabungan informasi GBIF dan EOL dapat menghasilkan informasi yang lebih banyak dan beragam.

Selanjutnya merancang antarmuka pengguna sesuai dengan informasi yang ingin ditampilkan. Tahap berikutnya adalah penulisan program dalam bahasa pemrograman PHP. Hasil pengembangan prototipe dapat dilihat pada Gambar 5.

Pengujian perlu dilakukan untuk memastikan informasi yang dihasilkan sesuai dengan perencanaan. Pengujian dilakukan pada setiap spesies tumbuhan obat. Berdasarkan hasil pengujian, beberapa tumbuhan yang dicari memiliki tingkatan taksonomi yang lengkap dari tingkat spesies sampai kingdom. Hasil pengujian lain seperti bawang merah (Allium Cepa Linn.) dan bawang putih (Allium Sativum Linn.) menghasilkan informasi tingkatan takson mulai dari tingkat genus sampai kingdom. Gambar tumbuhan obat dari hasil pencarian hanya menghasilkan informasi dari EOL. GBIF menghasilkan informasi tingkatan taksonomi tumbuhan lebih rinci, tetapi untuk informasi lain sinonim, nama lokal di negara lain, dan referensi lebih banyak yang berasal dari EOL.

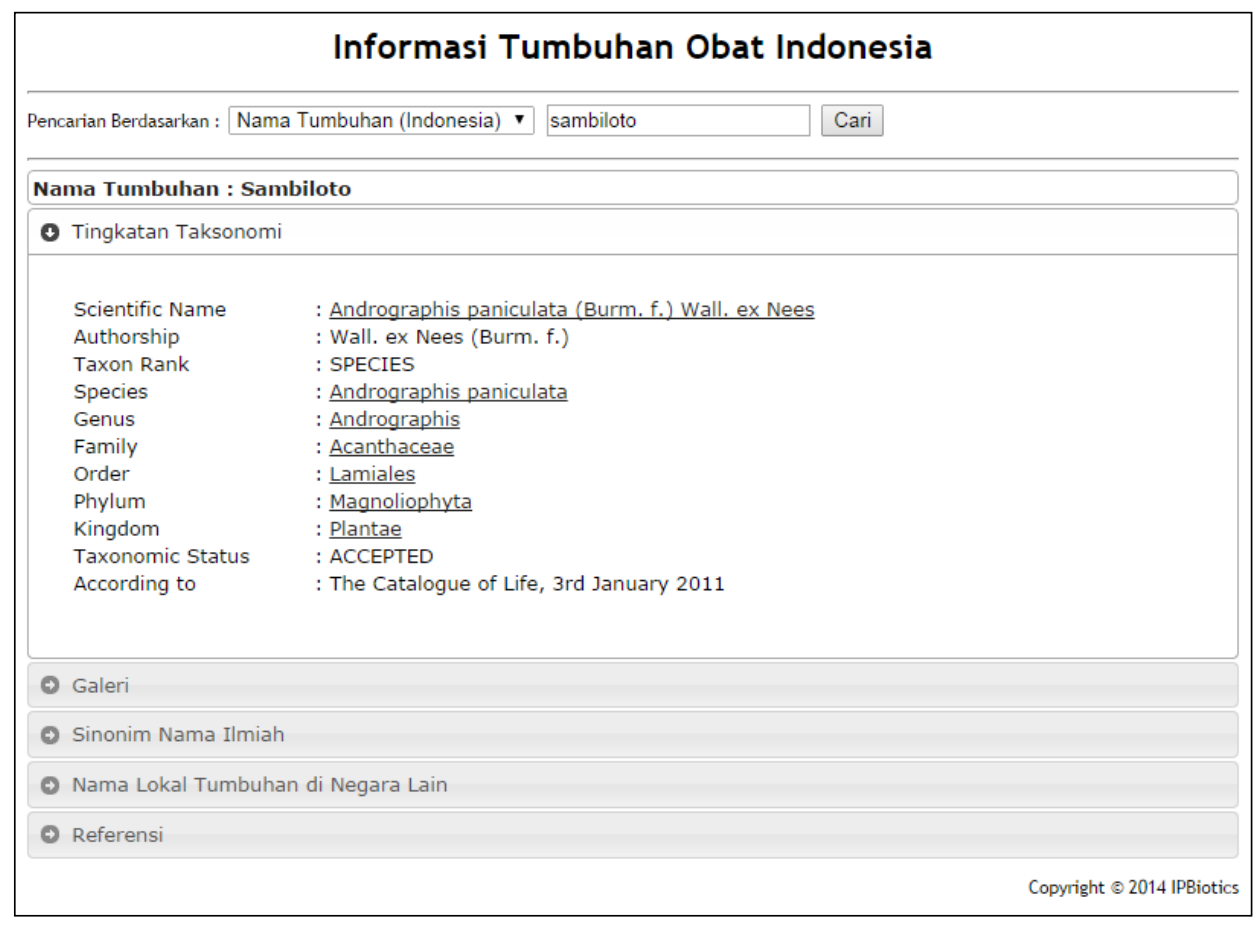

Gambar 5 Prototipe informasi tumbuhan obat Indonesia 


\section{SIMPULAN}

Global Biodiversity Infomation Facility (GBIF) dan Encyclopedia of Life (EOL) merupakan penyedia layanan web keanekaragaman hayati. Penggunaan fungsi API setiap penyedia layanan web harus disesuaikan dengan kebutuhan informasi yang ingin dihasilkan. Integrasi antar layanan web merupakan alternatif yang tepat jika penyedia layanan web memiliki fasilitas tersebut. GBIF dapat dijadikan sebagai sumber informasi tingkatan taksonomi tumbuhan karena informasi yang dihasilkan lebih rinci daripada EOL. Integrasi antara GBIF dan EOL membuat informasi tumbuhan obat yang dihasilkan lebih banyak dan beragam. Hasil prototipe pada penelitian ini diharapkan menjadi rekomendasi untuk ditambahkan pada pengembangan sistem informasi tumbuhan obat Indonesia.

\section{DAFTAR PUSTAKA}

Bappenas. 2003. Indonesia Biodiversity and Action Plan 2003-2020. Jakarta (ID): Bappenas.

Benslimane D, Dustdar S, Sheth A. 2008. Services Mashups. The New Generation of Web Applications. IEEE Internet Computing 12(5):13-15.

Constable H, Guralnick R, Wieczorek J, Spencer C, Peterson AT, VertNet Steering Committee. 2010. VertNet: a new model for biodiversity data sharing. PLoS biology 8(2):1-4.

Tavares DLM, Canete SC, Henkin R, Estrela PC, Freitas TRO, Galante R, Freitas CMDS. 2011. TaxonomyBrowser: a biodiversity data management system. Journal of Computational Interdisciplinary Sciences 2(1):37-46.

[EOL] Encyclopedia of Life. 2014. EOL API [Internet]. [diunduh 2014 Agustus 15]. Tersedia pada http://eol.org/api.

Flemons P, Guralnick R, Krieger J, Ranipeta A, Neufeld D. 2007. A web-based GIS tool for exploring the world's biodiversity: The Global Biodiversity Information Facility Mapping and Analysis Portal Application (GBIF-MAPA). Ecological Informatics 2(1):49-60.

[GBIF] The Global Biodiversity Information Facility. 2014. Spesies API version v0.9. Free and open access to biodiversity data [Internet]. [diunduh 2014 Agustus 15]. Tersedia pada http://www.gbif.org/developer/species.

Hamzari. 2008. Identifikasi tanaman obat-obatan yang dimanfaatkan oleh masyarakat sekitar hutan Tabo-tabo. Jurnal Hutan dan Masyarakat 3(2):159-167.

Jumali. 2006. Kajian potensi dan perumusan strategi pengembangan tumbuhan obat berbasis bioregonal di kabupaten Tapin [tesis]. Bogor (ID): Institut Pertanian Bogor.

Pressman RS. 2010. Software Engineering: a practitooner's approach 7th edition. New York (US): McGraw Hill.

Tjitrosoepomo, G. 2005. Taksonomi Umum. Dasar-dasar taksonomi tumbuhan, cetakan ke 3. Yogyakarta (ID): Gajah Mada University Press.

Tuominen J, Laurenne N, Hyvonen E. 2011. Biological names and taxonomies on the semantic web-managing the change in scientific conception. The Semanic Web: Research and Applications, Springer Berlin Heidelberg 255-269.

Wieczorek J, Bloom D, Guralnick R, Blum S, Doring M, Giovanni R, Robertson T, Vieglais D. 2012. Darwin Core: an evolving community-developed biodiversity data standard. PLoS ONE [Internet]. [diunduh 2014 Jan 17]; 7(1):1-8. Tersedia pada http://dx.plos.org/10.1371/journal.pone.0029715. 